\title{
PRIMARY REPAIR IS SUPERIOR TO INITIAL PALLIATION IN CHILDREN WITH ATRIOVENTRICULAR SEPTAL DEFECT AND TETRALOGY OF FALLOT
}

Hani K. Najm, MD

Glen S. Van Arsdell, MDa

Stefan Watzka, MD

Lisa Hornberger, $\mathrm{MD}^{\mathrm{b}}$

John G. Coles, MD

William G. Williams, MD
Objective: The objective was to explore the best management algorithm for atrioventricular septal defect in conjunction with tetralogy of Fallot. Methods: We reviewed the cases of 38 children referred to our division (March 1981-August 1997) who had atrioventricular septal defect associated with tetralogy of Fallot; $32(84 \%)$ had Down syndrome. Twentyone received initial palliation with a systemic-to-pulmonary artery shunt; of these, $2(\mathbf{9 . 5 \%})$ died before complete repair. Thirty-one children underwent complete repair; 14 of these $(45 \%)$ had undergone initial palliation (mean age at shunt $20 \pm 24$ months). Right ventricular outflow obstruction was relieved by a transannular patch in 22 (71\%); 14 (64\% of 22) had a monocuspid valve inserted. Four required an infundibular patch. Results: Two children (6.4\%) died early after repair; 1 had undergone previous palliation. Patients with palliation underwent repair at an older age (78 vs 36 months), required longer ventilatory support (8 vs 4 days) and inotropic support (8 vs 4 days), and had longer intensive care stays (11 vs 6 days) and hospital stays (24 vs 15 days). Eleven children $(35 \%)$ underwent reoperation, 7 (58\%) for right ventricular outflow reconstruction and pulmonary arterioplasty. Reoperation was more frequent in the palliation group than in the primary operation group ( $64 \%$ vs $12 \%)$. The single late death was related to a reoperation in the palliation group. Conclusions: Atrioventricular septal defect with tetralogy of Fallot can be repaired with a low mortality rate. Initial palliation with a shunt resulted in a more complex postoperative course and a higher reoperative rate. Primary repair is superior to initial palliation with later repair. (J Thorac Cardiovasc Surg 1998;116:905-13)
A trioventricular septal defect (AVSD) in association with tetralogy of Fallot (TOF) was first described in 1885 by Bull. ${ }^{1}$ The complex exhibits features of complete AVSD and TOF, specifically a nonrestrictive inlettype ventricular septal defect with anterior extension, an

From the Division of Cardiovascular Surgery, Department of Surgery, ${ }^{a}$ and the Division of Paediatric Cardiology, Department of Paediatrics, ${ }^{\mathrm{b}}$ The Hospital for Sick Children and the Faculty of Medicine, University of Toronto, ${ }^{\mathrm{a}, \mathrm{b}}$ Toronto, Ontario, Canada.

Read at the Seventy-eighth Annual Meeting of The American Association for Thoracic Surgery, Boston, Mass, May 3-6, 1998.

Received for publication May 20, 1998; revisions requested July 8, 1998; revisions received July 29, 1998; accepted for publication Aug 10, 1998.

Address for reprints: Glen Van Arsdell, MD, Cardiovascular Surgery, The Hospital for Sick Children, 555 University Ave, Toronto, Ontario M5G 1X8, Canada.

Copyright $@ 1998$ by Mosby, Inc.

0022-5223/98 $\$ 5.00+0 \quad \mathbf{1 2 / 6 / 9 3 7 6 3}$ ostium primum atrial septal defect, a common unpartitioned atrioventricular valve, anterosuperior deviation of the infundibular septum, and right ventricular outflow tract (RVOT) obstruction. AVSD associated with TOF affects the septa of both atria and ventricles and affects both ventricular inlets and outlets. The incidence of TOF in children with AVSD is $6 \%^{2}$; the incidence of AVSD in those with TOF is $1.7 \% .^{3}$ Reported mortality rates for complete repair in the past decade range between $3.9 \%$ and $33 \% .4,5$

Historically, the management of AVSD with TOF has been to provide palliation for the child with a systemicto-pulmonary artery shunt, followed by complete repair when the patient is older (usually 4-6 years old). ${ }^{6}$ The management of the RVOT has also been debated. Some authors ${ }^{7}$ recommend a transatrial-transventricular approach; others ${ }^{8}$ recommend a transatrial-transpulmonary approach, with avoidance of a ventricular incision if possible. The timing of the repair, the utility of a 
preliminary shunt, and techniques of RVOT repair have not been well defined in the literature.

In an effort to determine differential outcomes for different treatment algorithms, we reviewed the experience at our pediatric hospital. We compared repair at different ages, initial palliation versus primary repair, and different techniques of management of RVOT obstruction.

\section{Methods}

Between March 1981 and August 1997, 38 consecutive children with the diagnosis of AVSD associated with TOF were referred to the Division of Cardiovascular Surgery at The Hospital for Sick Children, Toronto, Canada. Thirty-two (84\%) had Down syndrome. Excluded from this analysis were children with double-outlet right ventricle-defined by more than $50 \%$ aortic override and aortic mitral separation, unbalanced AVSDs with severe hypoplasia of either of the ventricles requiring univentricular repair, and atrioventricular or ventriculoarterial discordance. Two children died between palliation and repair; 5 others who have undergone palliation await repair.

Details were collected from hospital and clinic records of presentation, cardiac catheterization reports, operative findings, techniques of repair, postoperative hospital course, and reoperations. Follow-up data were obtained by reevaluation of the child at the hospital, by telephone interview with parents, or by contact with the referring physician.

Repair technique. Thirty-one children have undergone complete repair. AVSD associated with TOF was repaired during standard cardiopulmonary bypass with bicaval cannulation, mild to moderate hypothermia $\left(28^{\circ}-32^{\circ} \mathrm{C}\right)$, and intermittent antegrade administration of blood cardioplegic solution. Mean cardiopulmonary bypass time was $115 \pm 25$ minutes (range 70-190 minutes); myocardial ischemic time was $89 \pm 21$ minutes (range 38-150 minutes). All pre-existing shunts were closed at initiation of cardiopulmonary bypass.

Management of septal defects. Most children ( $n=29)$ underwent closure of septal defects with a 2-patch technique; 2 children had a 1-patch repair. Ventricular patch material was polyethylene terephthalate fabric (Dacron) or autologous glutaraldehyde-treated pericardium fashioned into a comma shape. The wider portion of the patch was placed anteriorly, to ensure an unrestricted left ventricular outflow tract. A continuous suture technique was employed. Closure of the anterosuperior extension of the ventricular septal defect was aided by exposure through a right ventricular incision $(n=26)$.

Closure of the ostium primum atrial septal defect followed repair of the left atrioventricular valve. Autologous pericardium was used in all children. The inferior suture line followed the anulus of the left atrioventricular valve until clear of the conduction system and then was carried to the atrial septum. The coronary sinus was left to drain physiologically into the right atrium.

Management of atrioventricular valves. Competence of the left atrioventricular valve was assessed during cardio- plegic arrest by filling the left ventricle with cold saline solution. Multiple interrupted multifilament braided sutures were used to close the cleft without causing stenosis. The cleft in the left atrioventricular valve was completely closed in 20 patients; the remaining 11 had partial or no closure. The anterior bridging leaflet, posterior bridging leaflet, or both leaflets were divided in 11 children to improve exposure for accurate insertion of the ventricular patch.

Management of right ventricular outflow tract. The RVOT was explored from the atrium as well from an incision in the main pulmonary artery. The pulmonary valve was examined and commissurotomy was done if necessary. Transatrial resection of excessive right ventricular muscle bundles was performed to enlarge the outflow tract.

Graduated Hegar dilators were used to determine the pulmonary valve size. If the pulmonary valve was more than 1 or $2 \mathrm{~mm}$ smaller than the size estimates in standard charts, ${ }^{9}$ a transannular repair was performed. If the pulmonary valve ring was adequate but infundibular stenosis was severe, or if exposure of the subaortic region was poor, then a separate infundibular incision was made. RVOT obstruction was relieved by a transannular pericardial patch in 22 cases $(71 \%$ of 31 ), by an infundibular patch with preservation of the pulmonary valve in 4 cases (13\%), and by transatrial-transpulmonary repair in 5 cases $(16 \%)$. Among children who underwent transannular incision, 13 (59\% of 22) had a monocuspid valve inserted and 1 other $(5 \%)$ had insertion of a bioprosthetic pulmonary valve at the time of the initial repair.

Data analysis. Children undergoing complete repair ( $\mathrm{n}=$ 31) were subjected to a detailed analysis. This cohort was divided into 2 groups according to whether the child had undergone initial palliation before complete intracardiac repair. The 2 groups were then compared for preoperative, intraoperative, and postoperative variables. The incidences of late death and reoperation in the follow-up period were compared.

The children studied were also divided into 3 age groups ( $<2$ years, $\geq 2$ years and $<4$ years, and $\geq 4$ years) to help determine the best age range for repair. The effect of a ventricular incision on outcome was analyzed. For the purpose of the analysis, children who had infundibular incisions were grouped with children who had transannular incisions. To determine the effect of a competent pulmonary valve on outcome, children with a competent pulmonary valve (defined as those who had preservation of their native pulmonary valve or had a monocuspid valve or a pulmonary valve inserted) were compared with those who had a transannular incision without the insertion of a pulmonary valve. Trends in approach to management were examined by dividing the study period into 3 eras: 1981-1986, 1987-1991, and 19921997, inclusive. Kaplan-Meier curves were constructed to estimate survival and freedom from reoperation.

Age, weight, body surface area, preoperative and postoperative hemodynamic measurements, myocardial ischemic time, days of ventilatory support, days in the intensive care unit, and days in the hospital were taken as continuous variables. Categoric data included sex; the presence of Down syndrome, palliative shunt, cleft, or other anomalies; transan- 
Table I. Comparison of children with and without palliation

\begin{tabular}{|c|c|c|c|}
\hline \multirow[b]{2}{*}{ Variable } & \multicolumn{3}{|c|}{ Palliation before repair } \\
\hline & Yes & No & $\mathrm{P}$ \\
\hline Patients (n) & 14 & 17 & \\
\hline \multicolumn{4}{|l|}{ Preoperative } \\
\hline Age at repair (mo) & $78 \pm 52$ & $36 \pm 20$ & $<.01$ \\
\hline Weight $(\mathrm{kg})$ & $19 \pm 9$ & $12 \pm 4$ & $<.01$ \\
\hline Male (no.) & 5 & 9 & .05 \\
\hline Down syndrome (no.) & 11 & 14 & $>.1$ \\
\hline Age at initial examination (mo) & $5 \pm 7$ & $6 \pm 11$ & $>.1$ \\
\hline PAP $(\mathrm{mm} \mathrm{Hg})$ & $20 \pm 7$ & $25 \pm 11$ & $>.1$ \\
\hline RVP (mm Hg) & $100 \pm 10$ & $88 \pm 15$ & $>.1$ \\
\hline LVP (mm Hg) & $96 \pm 11$ & $88 \pm 15$ & $>.1$ \\
\hline Aortic saturation (\%) & $79 \pm 11$ & $81 \pm 14$ & $>.1$ \\
\hline \multicolumn{4}{|l|}{ Operative } \\
\hline Myocardial ischemia (min) & $86 \pm 28$ & $92 \pm 14$ & $>.1$ \\
\hline Transannular incision (no.) & 13 & 13 & $>.1$ \\
\hline Monocuspid valve (no.) & 8 & 6 & $>.1$ \\
\hline RVP, systolic (mm Hg) & $35 \pm 14$ & $38 \pm 9$ & $>.1$ \\
\hline PAP, systolic (mm Hg) & $29 \pm 15$ & $28 \pm 8$ & $>.1$ \\
\hline \multicolumn{4}{|l|}{ Postoperative } \\
\hline Use of inotropes (no.) & 12 & 14 & $>.1$ \\
\hline No. of inotropes per patient & 1.4 & 1.4 & $>.1$ \\
\hline Duration of inotropes (d) & $8 \pm 6$ & $4 \pm 3$ & .02 \\
\hline Ventilatory support (d) & $8 \pm 7$ & $4 \pm 3$ & .05 \\
\hline Stay in intensive care unit (d) & $11 \pm 9$ & $6 \pm 5$ & .06 \\
\hline Hospital stay (d) & $24 \pm 11$ & $15 \pm 6$ & $<.01$ \\
\hline Early death (no.) & 1 & 1 & $>.1$ \\
\hline \multicolumn{4}{|l|}{ Late follow-up } \\
\hline Late death (no.) & 1 & 0 & $>.1$ \\
\hline Reoperations (no.) & 9 & 2 & $<.01$ \\
\hline
\end{tabular}

$P A P$, Pulmonary artery pressure; $R V P$, right ventricular pressure; $L V P$, left ventricular pressure.

nular and infundibular incisions; monocuspid valve insertion; repair technique; closure of left atrioventricular valve cleft; death; and reoperation.

Data were analyzed with SPSS statistical software (release 6; SPSS Inc, Chicago, Ill). Continuous variables are expressed as means and were tested with a 2-tailed $t$ test. The $\chi^{2}$ and Fisher exact tests were used as appropriate to examine differences in proportions and categoric variables. Analysis of variance was used to test differences in continuous variables for different age groups. Data are generally presented as mean $\pm \mathrm{SD}$ (with or without a range).

\section{Results}

Preoperative data. The presenting symptom was cyanosis in 28 cases (90\% of 31). Mean age at presentation was $5.6 \pm 9$ months (0-31 months).

All children underwent cardiac catheterization before complete repair. The mean aortic saturation was $80 \% \pm$ $6 \%$. Right and left ventricular pressures were similar

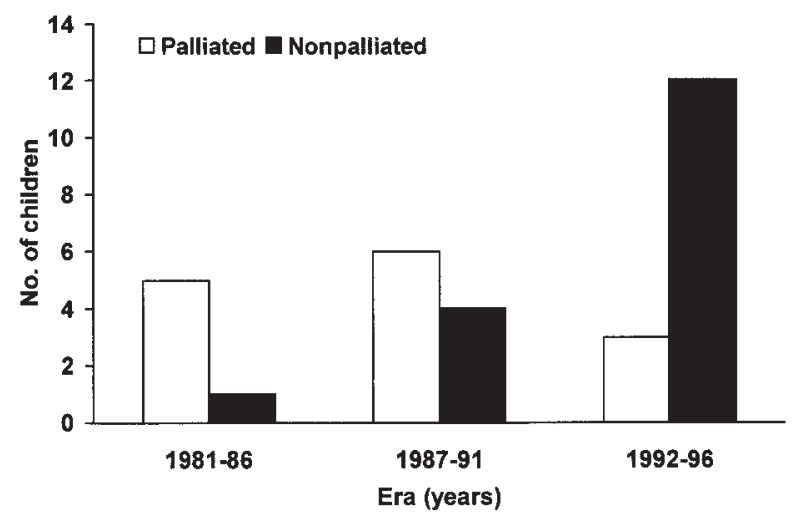

Fig 1. Proportions of children with shunting in different periods.

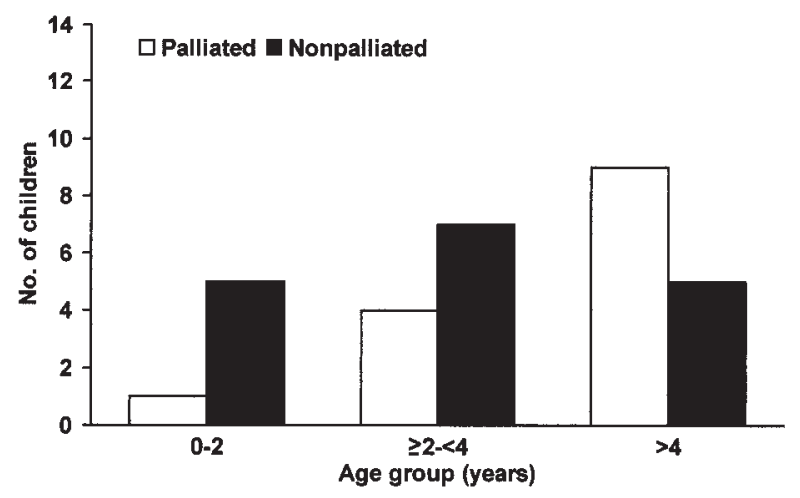

Fig 2. Proportions of children with shunting in different age groups.

(94 \pm 15 vs $92 \pm 12 \mathrm{~mm} \mathrm{Hg} ; P=.7$ ), and mean pulmonary artery systolic pressure was $24 \pm 10 \mathrm{~mm} \mathrm{Hg}$. Mean systemic-to-pulmonary flow was 1.6:1 (SD \pm $0.7)$. The Rastelli classification of the common atrioventricular valve was $\mathrm{B}$ in 1 child and $\mathrm{C}$ in the other 30. Three children had mild right ventricular hypoplasia, 8 had a right aortic arch, and 1 child had a doubleoutlet left atrioventricular valve.

Palliative procedures. Of the 38 children referred to our department, 21 (55\%) underwent palliation with a systemic-to-pulmonary shunt. Of these, 19 were Blalock-Taussig shunts, 1 was a central shunt, and 1 was an RVOT patch. Mean age at palliation was $20 \pm 24$ months (range 2-89 months). Two children died early (operative deaths) after the palliative procedure and before final repair, 14 underwent complete intracardiac repair at a mean interval of $46 \pm 26$ months (range 16-108 months), and 5 are awaiting final repair. There has been a trend toward primary repair in recent years (Fig 1). 
Table II. Outcome comparison for different groupings of 31 children with AVSD in association with TOF

\begin{tabular}{|c|c|c|c|c|c|c|c|c|c|}
\hline \multirow[b]{2}{*}{ Patient grouping } & \multirow[b]{2}{*}{$n$} & \multirow[b]{2}{*}{$\begin{array}{c}\text { Age at } \\
\text { repair (mo) }\end{array}$} & \multicolumn{2}{|c|}{ Duration } & \multicolumn{2}{|c|}{ Stay } & \multirow[b]{2}{*}{$\begin{array}{l}\text { Reop } \\
\text { (no.) }\end{array}$} & \multirow[b]{2}{*}{$\begin{array}{c}\text { Early death } \\
\text { (no.) }\end{array}$} & \multirow[b]{2}{*}{$\begin{array}{c}\text { Late death } \\
\text { (no.) }\end{array}$} \\
\hline & & & $\begin{array}{l}\text { Ino } \\
\text { (d) }\end{array}$ & $\begin{array}{l}\text { Vent } \\
\text { (d) }\end{array}$ & $\begin{array}{l}I C U \\
(d)\end{array}$ & $\begin{array}{l}\text { Hosp } \\
\text { (d) }\end{array}$ & & & \\
\hline Age $<2$ y & 6 & $15^{*}$ & 3 & 3 & 5 & 12 & 2 & 1 & 0 \\
\hline Age $\geq 2-<4$ y & 11 & $36^{*}$ & 9 & 9 & 11 & 21 & 4 & 0 & 1 \\
\hline Age $\geq 4 \mathrm{y}$ & 14 & $87 *$ & 4 & 5 & 6 & 18 & 5 & 1 & 0 \\
\hline Transannular incision & 26 & $62 \dagger$ & 4 & 5 & 6 & 16 & 10 & 2 & 1 \\
\hline No transannular incision & 5 & $20 \dagger$ & 19 & 15 & 23 & 34 & 1 & 0 & 0 \\
\hline Competent pulmonary valve & 23 & 49 & 7 & 6 & 6 & 18 & 9 & 2 & 1 \\
\hline Incompetent valve & 8 & 73 & 3 & 3 & 3 & 18 & 2 & 0 & 0 \\
\hline
\end{tabular}

Except for numbers of patients and reoperations, data are means. Ino, inotropic support; Vent, ventilatory support; ICU, intensive care unit; Hosp, hospital; Reop, reoperation.

*Significantly different from each other $(P<.05)$.

$\dagger$ Significantly different from each other $(P<.05)$

Intracardiac repair. Mean age at complete intracardiac repair was $55 \pm 42$ months (range 5-189 months). Of the 31 children who underwent complete repair, 14 had undergone previous palliation with a systemic-topulmonary shunt and 17 underwent primary repair. In recent years the percentage of primary repairs has progressively increased. In the first era (1981-1986) primary repair was performed in $17 \%$ of cases, in the second era (1987-1991) it was performed in 40\%, and in the recent era (1992-1997) it was performed in $80 \%(P$ $=.016$, Fig 1). Among the 3 children who underwent repair after palliation in the recent era, only 1 received palliation after 1990.

Characteristics of the palliation and primary repair groups are listed in Table I. Examination of preoperative variables revealed significant differences in age at intracardiac repair and in weight. The operative variables were more or less equal in the two groups. Analysis of postoperative variables revealed that the palliation group had significantly longer inotropic support, postoperative mechanical ventilation, and hospital stays than did children with primary repair.

Two early deaths occurred after intracardiac repair, 1 each in the palliation and primary repair groups. Both children had Down syndrome and both underwent transannular incision with construction of a monocuspid valve. One of these children required reoperation 6 days after repair to close a residual ventricular septal defect. Both died of myocardial failure.

Age at repair for 3 subgroups is illustrated in Fig 2. The chart demonstrates a higher proportion of children with palliation in the older age group $(P=.05)$. Comparison of outcomes demonstrates a slightly worse outcome in the older age groups, although this difference was not statistically significant $(P>.1$ for all variables tested; Table II). Older age at repair (62 vs 20 months) was associated with a higher likelihood of a transannular incision $(100 \%$ vs $50 \%, P=.01)$. Differences in other variables (listed in Table II) were not statistically significant, probably because of unequal numbers.

Fourteen children underwent insertion of a monocuspid valve in the RVOT during the initial operation. The "competent pulmonary valve" group did not show statistically significant differences in the variables tested compared with other children $(P>.1$ for all variables tested; Table II).

Follow-up. All but 1 of the children with palliation underwent repair in the earlier part of the series; they were therefore followed up for longer. Survivals at 4 years, including operative deaths in the calculation, have been $93 \%$ (95\% confidence interval [CI] 88\%$98 \%$ ) for the primary repair group and $82 \%(95 \% \mathrm{CI}$ $76 \%-88 \%)$ for the palliation group $(P=.5$, Fig 3$)$. There was 1 late death in the palliation group related to a reoperation 19 months after complete repair for repair of left atrioventricular valve regurgitation, closure of residual ventricular septal defect, and RVOT reconstruction.

Reoperations (Tables I and III) were more frequent in the palliation group. The median interval from complete repair to reoperation was 567 days (range 1 day-6.6 years). Freedom from reoperation at 4 years for the palliation group was $48 \%$ (95\% CI 41\%-55\%); it was $83 \%$ for the primary repair group $(95 \% \mathrm{CI} 78 \%-88 \%, P=$ .04 ; Fig 4). In the palliation group a trend continued in which freedom from reoperation at 10 years dropped to $21 \%$ (95\% CI $18 \%-24 \%)$. Length of follow-up in the primary repair group precluded analysis beyond 4 years.

\section{Discussion}

Intracardiac repair in children with AVSD associated with TOF is challenging for cardiac surgeons. As with 


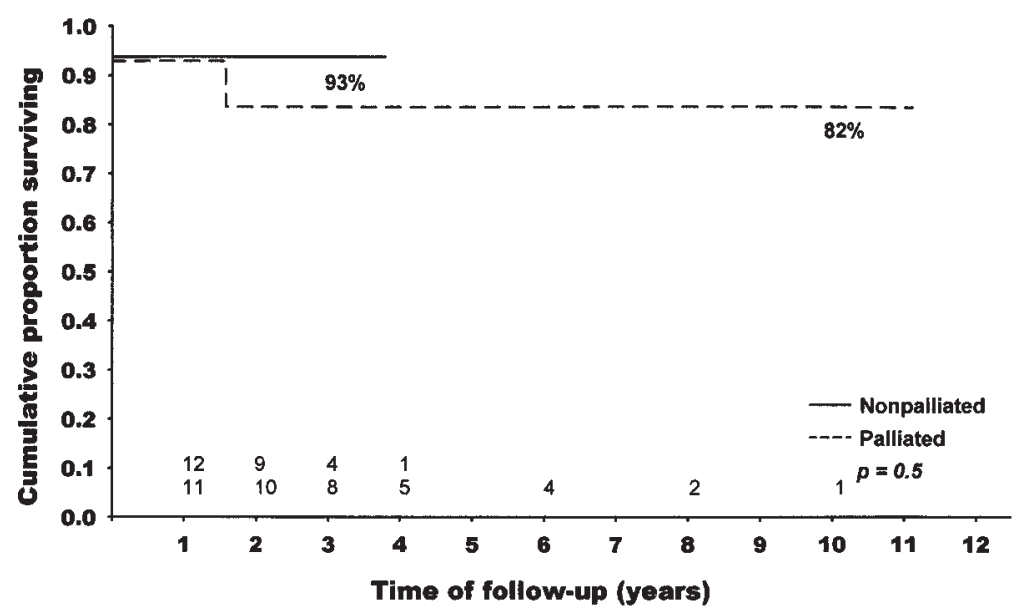

Fig 3. Kaplan-Meier survival curves for children who underwent palliation before repair and those who had primary repair without preceding palliation.

repair in cases of TOF, the age at clinical presentation depends on the degree of obstruction created by abnormalities in the RVOT. Most children first have symptoms beyond the neonatal or even the infant period. RVOT obstruction protects the pulmonary vasculature from the high pulmonary blood flow characteristic of complete AVSD, thereby allowing repair at an older age.

Previous recommendations for age of repair have been in the range of 4 to 6 years; palliation was performed in severely cyanotic children to allow them to reach that age.,3,6,10 However, palliation with later repair carries multiple potential complications, including prolonged cyanosis, excessive ventricular hypertrophy, volume loading of the ventricle, and onset or progression of atrioventricular valve regurgitation.

Expertise in primary repair in infants of isolated TOF or AVSD alone has become the standard of care, thereby raising the possibility of primary repair of AVSD associated with TOF. The mean age at palliation in this series and in previous reports ${ }^{3,8}$ is older than 1.5 years (in our series the mean was 20 months and the range was 2-89 months). Analysis of the data in our report demonstrates that primary repair at age 1 to 2 years, and even as young as 5 months, does not increase the early mortality rate. In comparisons with the older children, the data suggest that repair at a younger age is more favorable, as demonstrated by faster in-hospital recovery and lower incidence of reoperation for an equivalent duration of follow-up.

It is unusual for a child with AVSD associated with TOF to have symptoms in the first few months of life. In our series only 1 child required intervention at 2 months. After the first few months after birth, primary
Table III. Types of reoperation in each group

\begin{tabular}{lcc}
\hline Reoperation (no.) & Palliation & $\begin{array}{c}\text { Primary } \\
\text { repair }\end{array}$ \\
\hline RVOT and pulmonary artery reconstruction & 5 & 2 \\
Left atrioventricular valve repair & 4 & 0 \\
Residual ventricular septal defect & 4 & 0 \\
Subaortic stenosis & 1 & 0 \\
Glenn shunt & 1 & 0 \\
Total number of reoperations & $15^{*}$ & 2 \\
Total number of children & $11^{*}$ & 2
\end{tabular}

*Some combinations of multiple listed lesions were repaired.

repair of AVSD associated with TOF may be performed in most children brought for treatment. Heart failure during the neonatal period, although rare, would indicate an anatomic spectrum closer to complete AVSD, and in such a case early primary repair might be warranted. Severe cyanosis in the neonatal period indicates either severe RVOT obstruction or small pulmonary arteries. We speculate that a preliminary modified Blalock-Taussig shunt followed by early complete repair before complications from the shunt occur could be the procedure of choice. A recent alternative, catheter dilatation of the RVOT obstruction, is a possibility for temporization.

A modified Blalock-Taussig shunt may be indicated in unusual circumstances, such as small pulmonary arteries or a cyanotic neonate; however, the outcome for children undergoing palliation before repair in our series is less satisfactory than for children undergoing primary repair. Children in the palliation group had a more complex postoperative course and a higher preva- 


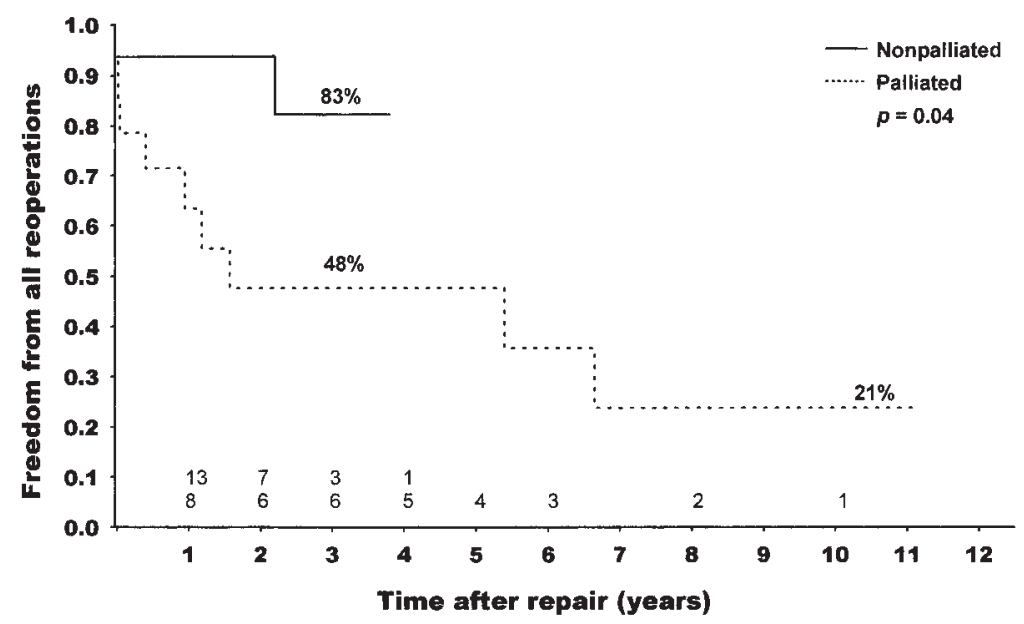

Fig 4. Freedom from reoperation curves for children who underwent palliation before repair and those who had primary repair without preceding palliation.

lence of reoperation. Additionally, prolonged volume loading of the ventricle and subsequent ventricular hypertrophy associated with long-term presence of a Blalock-Taussig shunt can affect the diastolic function of the heart, potentially complicating postoperative recovery. That these factors did not translate into an increased operative mortality rate is probably explained by the low event rate.

Techniques of repair reported have been variable. ${ }^{6,11-13}$ Regardless of the choice between a 1- or 2patch repair technique, division of the anterior bridging leaflet can improve exposure of the subaortic region for accurate closure of ventricular septal defects and preserve an unrestricted left ventricular outflow tract. To date we have treated only 1 child who required a reoperation for subaortic obstruction, 5.4 years after complete repair.

The right ventricle is compromised with inlet and outlet valvular lesions in AVSD associated with TOF. Competency of the right atrioventricular valve is probably more important, if not crucial, than in children with isolated AVSD. Additional commissuroplasty sutures or annuloplasty of the right atrioventricular valve may be required to maintain appropriate forward flow.

The appropriate management of the RVOT is debatable. A ventricular incision greatly enhances exposure of the subaortic region, which aids in the accurate insertion of a ventricular patch. In addition, hypertrophied right ventricular muscle bundles can be resected and the RVOT can be enlarged to eliminate any gradient. The drawback of this technique is the addition of a ventricular incision and, if the incision is transannular, acute or chronic pulmonary valve insufficiency.
A transatrial-transpulmonary repair without a ventricular incision was advocated by Malm and colleagues. ${ }^{8}$ Because of the long-term benefit of a competent pulmonary valve, preservation of pulmonary valve function is ideal. It is not always possible, however, as shown by the $50 \%$ incidence of a transannular incision reported from the same center, ${ }^{4,8}$ probably at the cost of a higher incidence of residual ventricular septal defects.

In an effort to determine the importance of a ventricular incision and pulmonary competence with respect to outcome, these 2 components were analyzed separately. Most of the children in our series $(n=26)$ underwent a ventricular incision. There was no difference in outcome according to hospital course or mortality rate. Children with a ventricular incision were significantly older than those without such an incision, however, perhaps because of increased ventricular hypertrophy at an older age.

There are contradictory reports ${ }^{14,15}$ about the efficacy of a monocuspid valve in the pulmonary position. For the purposes of our analysis, a pulmonary monocuspid valve was treated as a competent valve during the postrepair hospitalization. A monocuspid valve was created in $64 \%$ of children who underwent repair by a transannular incision (1 had implantation of a pulmonary valve). There was no improvement in outcome with respect to children who had a transannular incision without insertion of a pulmonary valve. The numbers of children in each group are small and unequal, however, precluding reliable tests of statistical significance.

It has been suggested that children who have AVSD with TOF associated with Down syndrome have a 
poorer outcome. ${ }^{4,10}$ Children with isolated AVSD and Down syndrome do not have a worse prognosis. ${ }^{2,16}$ Both deaths in this report were of children with trisomy 21 ; however, $84 \%$ of children in this series had Down syndrome. Data from this report are insufficient to render an observation regarding the relative risk with (0/6) or without (2/25) Down syndrome.

There are limitations to this study. It reports on an experience spanning 16 years, during which time important improvements in operative and postoperative care have evolved. Selection bias may be present, and treatment algorithms have changed. Certainly general advances in the field would bias the results in favor of better outcomes among the patients who underwent operation in the middle of 1990s than among those who underwent operation in the early 1980s. The inadequate numbers in some subgroups has also affected interpretation of the data.

Conclusions. Primary repair for children with AVSD associated with TOF can be performed with low risk, favorable intermediate survival, and acceptable reoperative rate and results. The need for initial palliation with a systemic-to-pulmonary shunt should be rare, and routine palliation may be detrimental. Repair at younger than 2 years is probably optimal. Neither the use of a ventricular incision nor the absence of a competent pulmonary valve adversely affected recovery time or outcome.

This article was prepared with the assistance of Editorial Services, The Hospital for Sick Children, Toronto, Ontario, Canada.

\section{REFERENCES}

1. Bull C. Anomalie congénital du coeur avec transposition des vesceres. Jemaine Med 1885;5:318.

2. Najm HK, Coles JG, Endo M, Stephens D, Rebeyka IM, Williams WG, et al. Complete atrioventricular septal defects: results of repair, risk factors, and freedom from reoperation. Circulation 1997;96(suppl 2):II311-5.

3. Arcinegas E, Hakimi, Farooki ZQ, Green EW. Results of total correction of tetralogy of Fallot with complete atrioventricular canal. J Thorac Cardiovasc Surg 1981;81:768-73.

4. Karl TR. Atrioventricular septal defect with tetralogy of Fallot or double-outlet right ventricle: surgical considerations. Semin Thorac Cardiovasc Surg 1997;9:26-34.

5. Bertolini A, Dalmonte P, Bava GL, Calza G, Lerzo F, Zannini L, et al. Surgical management of complete atrioventricular canal associated with tetralogy of Fallot. Cardiovasc Surg 1996;4:299302.

6. Pacifico AD, Kirklin JW, Bargeron LM. Repair of complete atrioventricular canal associated with tetralogy of Fallot or double outlet right ventricle: report of 10 patients. Ann Thorac Surg 1980;29:351-6.

7. Vouhe PR, Neveux JY. Surgical repair of tetralogy of Fallot with complete atrioventricular canal. Ann Thorac Surg 1986;41:342-4.
8. Malm T, Karl TR, Mee RB. Transatrial-transpulmonary repair of atrioventricular septal defect with right ventricular outflow tract obstruction. J Card Surg 1993;8:622-7.

9. Rowlatt UF, Rimoldi JH, Lev M. The quantitative anatomy of the normal child's heart. Pediatr Clin North Am 1963;10:499-506.

10. Uretzky G, Puga FJ, Danielson GK, Feldt RH, Julsrud PR, Seward JB, et al. Complete atrioventricular canal associated with tetralogy of Fallot: morphologic and surgical considerations. J Thorac Cardiovasc Surg 1984;87:756-66.

11. Alonso J, Nunez P, de Leon JP, et al. Complete atrioventricular canal and tetralogy of Fallot: surgical management. Eur J Cardiothorac Surg 1990;4:297-9.

12. Vargas FJ, Otero E, Mayer JE, Jonas RA, Castaneda AR. Complete atrioventricular canal and tetralogy of Fallot: surgical considerations. Ann Thorac Surg 1986;42:258-63.

13. Illbawi M, Cua C, DeLeon S, et al. Repair of complete atrioventricular septal defect with tetralogy of Fallot. Ann Thorac Surg 1990;50:407-12.

14. Gundry SR, Razzouk AJ, Boskind JF, Bansal R, Bailey LL. Fate of the pericardial monocusp pulmonary valve for right ventricular outflow tract reconstruction: early function, late failure without obstruction. J Thorac Cardiovasc Surg 1994;107:908-13.

15. Bigras JL, Boutin C, McCrindle BW, Rebeyka IM. Short-term effect of monocuspid valves on pulmonary insufficiency and clinical outcome after surgical repair of tetralogy of Fallot. J Thorac Cardiovasc Surg 1996;112:33-7.

16. Hanley FL, Fenton KN, Jonas RA, Mayer JE, Cook NR, Wernovsky G, et al. Surgical repair of complete atrioventricular canal defects in infancy: twenty-year trends. J Thorac Cardiovasc Surg 1993;106:387-97.

\section{Discussion}

Dr Hillel Laks (Los Angeles, Calif). The group has presented data spanning a more than 16-year period, in which presumably different surgeons employed different techniques, and a strategy that in the earlier time period involved shunting and later on primary repair. I am not sure that the results, which were based on such outcomes as length of stay in the intensive care unit, duration of inotropic support, duration of ventilator support, and reoperations, can necessarily be used as a basis to confirm the conclusions in such a retrospective study. We do, however, agree completely with the conclusion that primary repair is the preferred approach. If one looks at the periods of presentation, shunting, and repair, these children apparently were first seen at about 5.6 months, the average age at shunting was 20 months, and for the second-stage repair the average age was 78 months.

Do you have the data of children who are seen at 5.6 months? If so, were there deaths, as apparently did not occur in this series of patients operated on, if one were to look at all patients, not only those who eventually ended up with a repair? That is, would there be deaths while waiting for the shunt, which was delayed to an average of 20 months, and then again while waiting for the complete repair?

The second point is about your current institutional policy. I think that most groups when presented with a child of about 6 months with this condition would proceed in the presence of cyanosis to do a complete repair, rather than delaying 
either the shunt or the definitive procedure, and I would like to ask what the policy is now with respect to such a patient.

It could be asked whether one could justify a palliative shunt in the very young, and I think there were 1 or 2 in your series younger than 3 months. What is the policy within your institution for that type of patient?

From the point of view of the technical details of the myocardial protection, there were 2 deaths, both of myocardial failure, and the duration of inotropic support was 4 days in the primary repair group and 8 days in the delayed group. One thing that we have found useful in myocardial protection for such children is retrograde cardioplegic solution given with a purse-string suture around the coronary sinus, which helps in deairing the root of the aorta when one is repeatedly testing the atrioventricular valves, prevents repeated air embolization each time one does this type of testing, and allows one to repeat the cardioplegic treatment without stopping the operation every 10 minutes. I would like to hear what the myocardial protection was during this 16-year period, which may also explain the differences in the results between the 2 groups.

With respect to the 1- or 2-patch technique, the data are extremely interesting in that a 2-patch technique was used in all but 1 case. In this anatomic situation a problem is the exposure of the anterosuperior aspect, particularly with the overriding aorta, and an advantage of the 1-patch technique and division of the superior bridging leaflet is improved exposure of that anterosuperior aspect. To achieve this with this 2-patch technique that was used, 26 of the patients underwent a ventriculotomy to suture the anterosuperior part of the patch and 11 patients underwent division of the superior bridging leaflet to expose that part of the ventricular septal defect. I submit that, particularly in this group of patients, a single-patch technique might be preferable to avoid the ventriculotomy and to obtain complete repair without residual ventricular septal defects, as occurred in a significant number of these patients. Could you comment on your approach with 1- versus 2-patch technique?

Finally, with respect to the tricuspid valve and the monocuspid valve, please comment on how many of the monocuspid valves were studied by echocardiography and were in fact competent, because the pericardial technique is not always reliable in achieving a competent pulmonary valve. Was it necessary in some cases, as we have found, to add some sutures to the tricuspid valve repair? It becomes much more crucial in these patients to have a completely competent tricuspid valve.

Dr Najm. We agree with you that this was a retrospective review and that it has limitations. We tried to base our conclusions on reasonably clear data.

With respect to mortality rates among younger children versus older children, we had only 2 deaths and both of them were in the older age group; 1 had undergone shunting and the other had not, both had Down syndrome, and both had transannular incisions. I am not able to add any further comment because of the low number of deaths. We had 2 children die shortly after the shunt procedure and before complete repair; these were considered operative deaths related to the shunt procedure. We had no deaths between successful shunting and complete repair.

Our policy with respect to a neonate first seen with cyanosis before 3 months would be referral of the child to an interventional cardiologist for balloon dilatation of the RVOT to temporize until the child is older and can undergo complete intracardiac repair. If this cannot be done and the child has small pulmonary arteries, I think that a Blalock-Taussig shunt would be a better choice in this age group. After 3 months, if the anatomy is suitable and the pulmonary arteries are adequate, and especially if there are signs and symptoms of heart failure, we would consider complete repair.

With respect to your question regarding the use of retrograde cardioplegic administration, this is indeed a valuable technique, but we have not used it. The study period spans, as you indicated, more than 16 years; during this period we used antegrade intermittent administration of cold blood cardioplegic solution. Recently we have started to use retrograde cardioplegic administration in some of these cases, but children in this series did not have retrograde cardioplegic administration. Because protection of the right ventricle may be suboptimal with this technique and because of the precarious state of the right ventricle, I would have some reservation in relying exclusively on retrograde cardioplegic administration.

As far as the technique is concerned, as I am sure you are all aware the right ventricle is compromised by the inlet valve, the right atrioventricular valve, as well as by the outlet valve, the pulmonary valve. We looked back at the results of children who had a ventricular incision and compared them with those of children who did not. The outcome was, at least, not worse, suggesting that the impact of a ventricular incision does not affect early results. However, there was a higher reoperation rate among children with a ventricular incision.

We do for the most part use a 2-patch technique in most cases, and 11 children indeed had division of the bridging leaflet. This is done to improve exposure, and we have also adopted a technique of using the ventricular patch to augment the left atrioventricular valve, to improve the repair that requires division of the leaflets. We published this technique in the November 1997 Circulation supplement. ${ }^{2}$

Ideally we prefer to avoid a ventricular incision; nevertheless, in this particular subgroup of patients there were 26 children who underwent a ventricular incision, the indication for which was not exclusively based on exposure. Some of these children underwent a ventricular incision for a hypoplastic RVOT.

In terms of the monocuspid valve, again, because the study period spans more than 16 years we used different techniques of monocuspid valve reconstruction. In the initial part of the series we used autologous pericardium sutured on the table to another piece of pericardium; this whole complex was then sutured to the outflow tract. In recent years we have used the Loma Linda technique of monocuspid valve construction, in which implantation of the pericardial patch in the RVOT is followed by placement of an onlay outflow patch. We have 
recently looked at the outcome with the older technique of insertion of a monocuspid valve; unfortunately, these monocuspid valves have limited benefit in the early postoperative period and no benefit in the late follow-up. Inserting a monocuspid valve thus does not in itself mean that you have a functional pulmonary valve. In our series a lot of the patients who had a transannular incision and insertion of a monocuspid valve underwent a late reoperation. Also, we think that the presence of a monocuspid valve may in time become restrictive when it is stuck in the open position, and it may predispose toward reoperation because of RVOT obstruction.

With respect to the tricuspid valve repair, we are concerned, as you would imagine, about the function because of compromise of the right ventricle. In addition these patients might be losing their pulmonary valve as well, so special attention is paid to the right atrioventricular valve to try and improve the function. We did insert annuloplasty and repair sutures in some cases. We are certainly more careful with respect to the function of the right atrioventricular valve in this subgroup of children with associated TOF than in the group of children with isolated complete atrioventricular canal.

Dr Roger B. B. Mee (Cleveland, Ohio). There are problems with these long retrospective studies, and with the way you put the data together. It has become important to be able to say at a meeting now that you prefer primary repair. Could you comment perhaps on the possible relationship between the need to shunt, the need for a transannular patch, and the need for reoperation?

Second, the operations were done pretty late after the patients underwent shunting. Did you wait until the shunt was clearly inadequate? What I am trying to get at is that if the patient is quite blue when coming to repair, then at the time of repair you are volume loading the heart and have probably added a leaking pulmonary valve, which may make postoperative care more difficult. It would seem to me that those patients in whom you were able to do a primary repair without a shunt perhaps had a more volume-loaded heart than did those that underwent shunting before the repair. It is my view that if the heart is volume loaded, then the common atrioventricular valve is bigger and it makes it a little easier to septate this type of heart and have 2 adequately sized atrioventricular valves.

If the patient is extremely blue before the operation, the chambers of the heart are smaller and the probability is that you have had to do a transannular patch because of an inadequate outlet. In addition, the inlets are smaller. I think that all these factors would do much to militate a long time in the intensive care unit, more inotropes, and so forth. I thus think that there are several ways in which your data could be interpreted.

I have 2 questions. First, what is the relationship between the need for a transannular patch, the need for an early shunt, and the need for reoperation? Second, could you comment on the saturations of the patients before the final repair, as a hint to volume loading?

Dr Najm. With respect to the relationship between the shunt, a transannular patch, and reoperation, we would consider shunting in neonates who are seen before 3 months who are significantly blue and have small pulmonary arteries, as I indicated. Children first seen at an older age would be considered for primary repair.

The need for a transannular patch would be higher among patients who are cyanotic because of the severity of RVOT obstruction. We believe that the presence of a shunt may add a volume overload on the heart, but right-sided chamber size may not be affected by this load. Children who are deeply cyanotic, as you indicated, may have small right-sided chambers compounded with right ventricular hypertrophy. Your comment on the repair of the valve with a volume-loaded heart is valid. We have not analyzed our data in this respect; however, it is certainly an interesting concept.

The need for reoperation in our subgroup of patients was based on RVOT obstruction, residual ventricular septal defects, or left atrioventricular valve regurgitation. Although children who underwent a transannular patch had a favorable outcome, they also had a higher incidence of reoperation. 